15.2

\title{
Моделирование заряд-разрядных характеристик суперконденсаторов на основе эквивалентной схемы с фиксированными параметрами
}

\author{
() Д.С. Ильющенков, А.А. Томасов, С.А. Гуревич \\ Физико-технический институт им. А.Ф. Иофффе РАН, Санкт-Петербург, Россия \\ E-mail: dmitry@mail.ioffe.ru
}

Поступило в Редакцию 24 сентября 2019 г.

В окончательной редакции 16 октября 2019г.

Принято к публикации 21 октября 2019 г.

\begin{abstract}
Показана возможность описания заряд-разрядных характеристик суперконденсаторов с электродами из пористого углерода с помощью простой эквивалентной схемы с постоянными величинами емкостей и сопротивлений. С помощью численного моделирования показано, что существует связь между параметрами эквивалентной схемы и структурой пор электродного материала. Результаты моделирования указывают также на неоднородный характер заряжения различных групп пор электродного материала в структуре суперконденсатора.
\end{abstract}

Ключевые слова: суперконденсатор, заряд-разрядная характеристика, эквивалентная схема, моделирование.

DOI: 10.21883/PJTF.2020.02.48950.18048

В последнее время наблюдается значительный прогресс в области разработки суперконденсаторов (СК) накопителей электрической энергии, которые, как ожидается, могут по основным техническим параметрам превзойти широко используемые литий-ионные аккумуляторы [1-3]. По сравнению с литий-ионными аккумуляторами СК могут обеспечивать бо́льшую мощность при разряде и меньшее время заряда, обладают более высокой надежностью. Однако по удельной накапливаемой энергии СК все еще значительно уступают литийионным аккумуляторам, что в значительной мере сдерживает их широкое применение в целом ряде областей техники [4-6].

В наиболее простом случае СК состоит из двух электродов, разделенных тонким слоем электролита, содержащим подвижные ионы, катионы и анионы. При приложении внешнего напряжения заряды накапливаются в двойном электрическом слое на поверхности электродов [7]. В качестве электродных материалов в СК часто используются различные формы проводящего пористого углерода, в том числе так называемый активированный углерод, обладающий удельной поверхностью более $2000 \mathrm{~m}^{2} / \mathrm{g}$ [8]. Большая величина удельной поверхности является ключевым свойством электродного материала, обеспечивающим высокую емкость СК. Для работы СК важно также, чтобы в электродном материале имелся достаточно широкий набор размеров пор. При этом самые мелкие поры, вносящие, как правило, основной вклад в величину удельной поверхности, становятся доступны для ионов электролита через более крупные поры, что обеспечивает малое внутреннее сопротивление и высокую мощность СК. Вопрос о влиянии параметров пористости электродных материалов на электрические характеристики СК обсуждался в литературе как на основании экспериментальных данных [9], так и с при- влечением результатов численного моделирования на основе анализа характеристик распределенных $R C$-цепей [10-12]. Важные данные о взаимосвязи структуры пор электродного материала с быстродействием СК были получены в работе [13]. Однако до настоящего времени не удавалось получить наглядную картину связи между параметрами пор и основными характеристиками СК.

В настоящей работе предлагается простой подход к описанию характеристик СК с помощью эквивалентной схемы, содержащей минимальное количество элементов: емкостей и сопротивлений. С помощью численного моделирования показано, что экспериментальные зарядразрядные характеристики СК с электродами из активированного углерода хорошо описываются во всем диапазоне рабочих напряжений с использованием эквивалентной схемы с постоянными величинами емкостей и сопротивлений. Такой подход позволяет на качественном уровне установить связь между элементами схемы и параметрами пор электродного материала. Результаты моделирования показывают наличие существенной неоднородности заряжения и разряда различных групп пор в структуре СК.

Моделирование заряд-разрядных характеристик СК с электродами на основе активированного углерода проводилось с помощью эквивалентной схемы, представленной на рис. 1. Данная схема содержит три емкости $\left(C_{0}, C_{1}\right.$ и $\left.C_{2}\right)$, которые соответствуют трем раздельным группам пор электродного материала. Такое представление основано на том, что, как известно, различные формы активированного углерода содержат чаще всего две-три выделенные группы пор с размерами от нескольких нанометров до субнанометровых, причем наиболее мелкие поры имеют, как правило, наибольший объем и вносят наибольший вклад в емкость. В целом структура 
Параметры эквивалентной схемы суперконденсатора

\begin{tabular}{c|c|c|c|c|c}
\hline$C_{0}, \mathrm{mF} / \mathrm{cm}^{2}$ & $C_{1}, \mathrm{mF} / \mathrm{cm}^{2}$ & $C_{2}, \mathrm{mF} / \mathrm{cm}^{2}$ & $R_{0}, \Omega \cdot \mathrm{cm}^{2}$ & $R_{1}, \Omega \cdot \mathrm{cm}^{2}$ & $R_{2}, \Omega \cdot \mathrm{cm}^{2}$ \\
\hline 33 & 30 & 30 & 10 & 950 & 1700
\end{tabular}

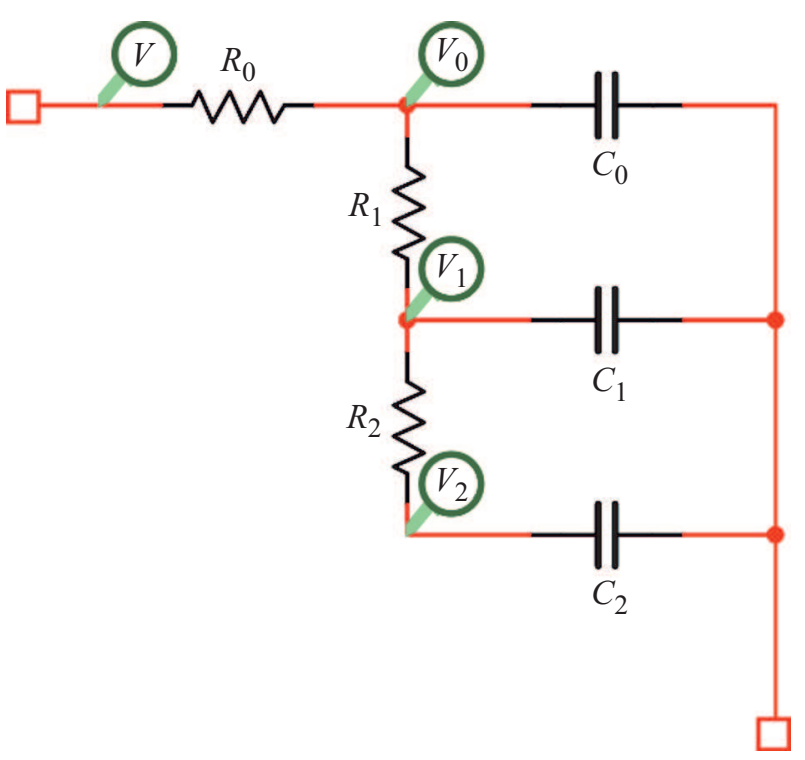

Рис. 1. Эквивалентная схема суперконденсатора.

пор представляется в виде „ветвей дерева“ [14], при этом доступ ионов к поверхности в каждой следующей группе более мелких пор осуществляется по заполненным электролитом каналам в предыдущей группе более крупных пор. В соответствии с такой организацией структуры материала в схеме на рис. 1 ток к каждой из емкостей протекает через сопротивление. Структура пор типа „ветвей дерева“ предполагает также, что в ряду сопротивлений выполняется соотношение $R_{0}<R_{1}<R_{2}$. Сопротивление $R_{0}$ включает в себя помимо ионного сопротивления в группе самых крупных пор также сопротивление электролита в зазоре между электродами, сопротивление коллекторов тока и контактов. Отметим также, что схема на рис. 1 представляет одновременно оба электрода СК, т. е. элементы этой схемы описывают распределение заряда, токов и потенциалов, усредненное по обоим электродам СК. Анализ показывает, что в действительности такое упрощенное представление не приводит к потере существенных особенностей заряд-разрядных характеристик СК. Расчеты распределения напряжений и токов в схеме, показанной на рис. 1, проводились с использованием пакета программ Comsol Multiphysics 5.4 .

На рис. 2 символами показана типичная экспериментальная разрядная характеристика СК с электродами из активированного углерода (подобные кривые приведены, например, в [15-17]). На этом же рисунке сплошная линия - результат моделирования разрядной кривой по схеме, представленной на рис. 1. Как видно, расчетная характеристика близка к экспериментальной. Величины емкостей и сопротивлений, обеспечивающие наилучшее совпадение кривых, приведены в таблице.

На рис. 3 показаны результаты расчета зависимости потенциала от времени при нескольких циклах зарядаразряда СК. Расчет проводился с имитацией гальваностатического режима циклирования СК, при этом на каждом цикле заряда и разряда на вход схемы (рис. 1) с параметрами элементов, указанными в таблице, подавался постоянный ток $1 \mathrm{~mA} / \mathrm{cm}^{2}$. При переходе от заряда к разряду ток меняет направление без изменения абсолютной величины. Отметим, что на приведенном рисунке кривые временно́й зависимости внешнего потенциала $V$ и потенциала $V_{0}$ на емкости $C_{0}$ практически совпадают, что в данном случае является следствием малого сопротивления $R_{0}$ и малого тока заряда-разряда. Очевидно, что при увеличении тока кривые для $V$ и $V_{0}$ будут различаться, при этом при переключении направления тока появятся характерные скачки потенциала [15].

Рис. 3 иллюстрирует важную особенность работы суперконденсаторов, состоящую в том, что емкости, соответствующие различным группам пор электродного материала, заряжаются и разряжаются несинхронно. Как видно из рисунка, чем больше емкость, тем меньше величина перепада напряжения на ней, при этом имеется характерное запаздывание во времени заряда-разряда больших емкостей. С учетом того, что большие емкости соответствуют мелким порам с большой удельной

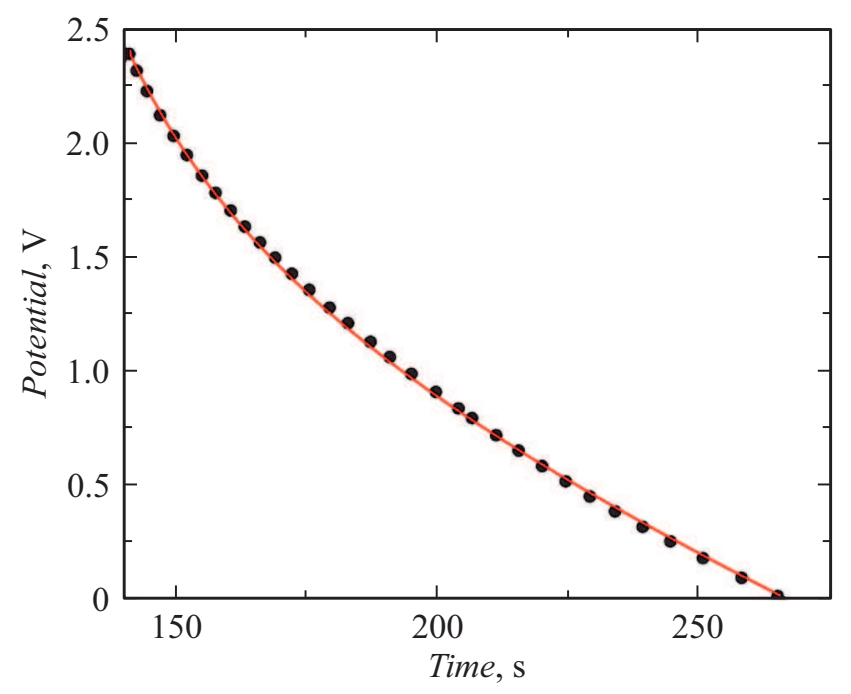

Рис. 2. Разрядная характеристика суперконденсатора с электродами на основе активированного углерода. Символы эксперимент, сплошная линия - расчет. 


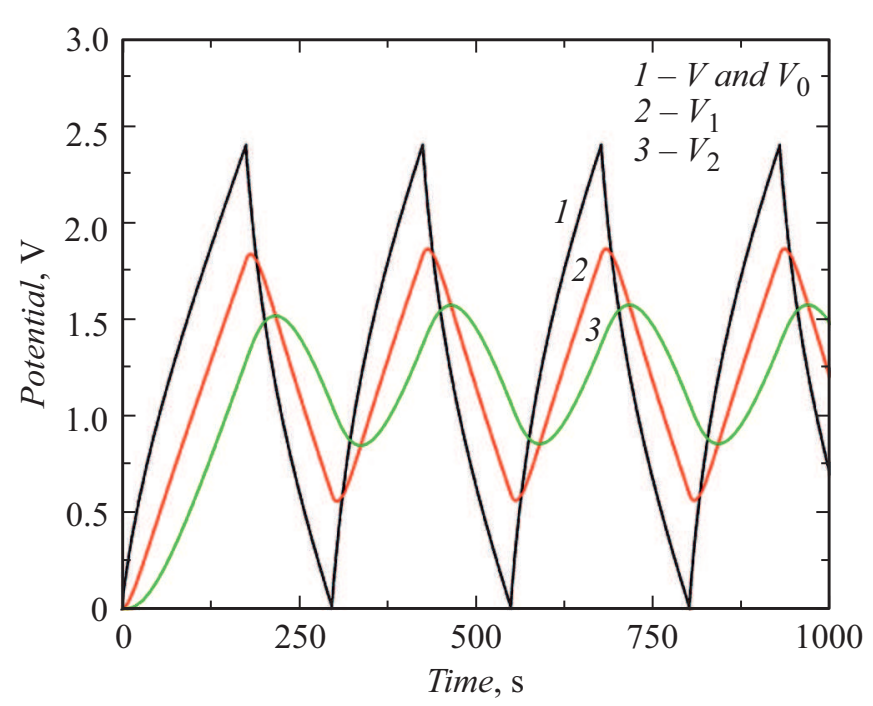

Рис. 3. Расчетные зависимости напряжения от времени при циклическом заряде-разряде СК. Разные кривые показывают изменение напряжения в различных точках схемы, представленной на рис. 1.

поверхностью, такое поведение означает неполное накопление заряда на поверхности мелких пор и соответственно неполную реализацию возможности накопления заряда в СК при заданном внешнем напряжении заряда-разряда.

Отметим, что обсуждаемая неоднородность заряжения различных групп пор является принципиально неустранимым эффектом в СК с электродными материалами, имеющими структуру пор типа „ветвей дерева“. Мы полагаем, что разработанный алгоритм моделирования работы СК на основе эквивалентной схемы с постоянными в рабочем диапазоне напряжений сопротивлениями и емкостями позволяет оптимизировать структуру используемых электродных материалов и улучшить характеристики СК.

\section{Финансирование работы}

Работа выполнена в рамках темы госзадания ФТИ им. А.Ф. Иоффе.

\section{Конфликт интересов}

Авторы заявляют, что у них нет конфликта интересов.

\section{Список литературы}

[1] Berrueta A., Ursua A., San Martini I., Eftekhari A., Sanchis P. // IEEE Access. 2019. V. 7. P. 50869-50896.

[2] Wang F., Wu X., Yuan X., Liu Z., Zhang Y., Fu L., Zhu Y., Zhou Q., Wu Y., Huanga W. // Chem. Soc. Rev. 2017. V. 46. P. 6816-6854.

[3] Choudhary N., Li Ch., Moore J., Nagaiah N., Zhai L., Jung Y., Thomas J. // Adv. Mater. 2017. V. 29. P. 1605336.
[4] Aneke M., Wang M. // Appl. Energy. 2016. V. 179. P. 350377.

[5] Cao J., Emadi A. // IEEE Trans. Power Electron. 2012. V. 27. P. $122-132$.

[6] Simon P., Gogotsi Y., Dunn B. // Science. 2014. V. 343. P. 1210-1211.

[7] Conway B.E. // J. Electrochem. Soc. 1991. V. 138. P. 15391548.

[8] Gamby J., Taberna P.L., Simon P., Fauvarque J.F., Chesneau M. // J. Power Sources. 2001. V. 101. P. 109-116.

[9] Chmiola J., Yushin G., Gogotsi Y., Portet C., Simon P., Taberna P.L. // Science. 2006. V. 313. P. 1760-1763.

[10] Logerais P.-O., Camara M.A., Riou O., Djellad A., Omeiri A., Delaleux F., Durastanti J.F. // Int. J. Hydrogen Energy. 2015. V. 40. P. $13725-13736$.

[11] Pean C., Rotenberg B., Simon P., Salanne M. // J. Power Sources. 2016. V. 326. P. 680-685.

[12] Fletcher S., Kirkpatrick I., Dring R., Puttock R., Thring R., Howroyd S. // J. Power Sources. 2017. V. 345. P. 247-253.

[13] Компан М.Е., Малышкин В.Г. // Письма в ЖТФ. 2019. T. 45. B. 2. C. 47-49.

[14] Yang H., Ye S., Zhou J., Liang T. // Front Chem. 2019. V. 7. P. 274.

[15] Ahmed S., Ahmed A., Rafat M. // J. Saudi Chem. Soc. 2018. V. 22. P. $993-1002$.

[16] Sim Ch-K., Majid S.R., Mahmood N.Z. // Int. J. Electrochem. Sci. 2015. V. 10. P. 10157-10172.

[17] Rodrigues A.C., Leal da Silva E., Quirino S.F., Cuña A., Marcuzzo J.S., Matsushima J.T., Gonçalves E.S., Baldan M.R. // Mater. Res. 2019. V. 22. P. e20180530. 